02,11

\title{
Скачкообразные квантовые фазовые переходы в вихревой системе и динамическая комплексная магнитная проницаемость двойниковых $\mathrm{YBa}_{2} \mathrm{Cu}_{3} \mathrm{O}_{7-x}$ высокотемпературных сверхпроводников
}

\author{
(C) X.P. Ростами
}

Фрязинский филиал Института радиотехники и электроники им. В.А. Котельникова РАН., Фрязино, Московская обл., Россия

E-mail: rostami@ms.ire.rssi.ru

Поступила в Редакцию 11 мая 2021 г.

В окончательной редакции 5 сентября 2021 г.

Принята к публикации 15 октября 2021 г.

\begin{abstract}
Для одновременного выяснения объемного и локального характера скачкообразного проникновения магнитного потока через границы двойникования в $\mathrm{YBa}_{2} \mathrm{Cu}_{3} \mathrm{O}_{7-x}$ ВТСП-образец при его скачкообразном „распаде“ на двойники, разработан локальный высокочастотный метод измерения динамической комплексной магнитной проницаемости с повышенным пространственным разрешением. По значениям полей, соответствующих областям скачков, определены термодинамические первые критические магнитные поля: проникновения потока в образец в джозефсоновскую среду; установления критического состояния в джозефсоновской среде; проникновения потока в двойники; скачкообразных квантовых фазовых переходов в вихревой системе ВТСП-образца соответственно, плавления вихревого кристалла и течения вихревой жидкости, образования в образце состояния сверхпроводящего стекла, перехода в состоянии вихревого стекла и брэгговского стекла.
\end{abstract}

Ключевые слова: высокочастотная индуктивность, объемная и локальная динамическая комплексная магнитная проницаемость, захват магнитного потока, эффективный размагничивающий фактор, двойники, границы двойникования.

DOI: 10.21883/FTT.2022.02.51945.107

\section{1. Введение}

Несмотря на интенсивные исследования физических свойств высокотемпературных сверхпроводников (ВТСП) с момента их открытия [1] и накопленного огромного экспериментального и теоретического материала, до сих пор окончательно не установлен механизм сверхпроводимости, позволяющей единым образом описать полученные результаты. Фундаментальные проблемы, приводящие к столь низкой плотности критического тока $J_{c}$ в ВТСП, также окончательно не выяснены, что не позволяет найти технологические рецепторы повышения $J_{c}$ в ВТСП-материалах. Вместе с этим известно, что концентрация носителей заряда (дырок) в ВТСП $(0.7-1) 10^{22} \mathrm{~cm}^{-3}$ на порядок ниже, чем носители заряда в традиционных металлических сверхпроводниках, а длина когерентности в ВТСП $-\xi \sim 5-10 \AA$ вдоль оси $c$ и $20-35 \AA$ в плоскости $[a b]$ в свою очередь 5-10 раз меньше, чем в металлических сверхпроводниках. Для более доступного с технологической точки зрения $\mathrm{YBa}_{2} \mathrm{Cu}_{3} \mathrm{O}_{7-x}$ (YBCO) также установлено, что даже самые совершенные монокристаллы ҮВСО содержат в себе большое количество регулярно расположенных границ двойникования (ГД) с плоскостью двойникования (110). В зависимости от способа приготовления материала ГД могут иметь ширину $\Delta d \sim 30-50 \AA$, а расстояние между ГД может составлять $d \sim 200-2000 \AA[2-5]$.
Такое соотношение параметров приводит к тому, что физические свойства слоистых ВТСП становятся очень чувствительными к незначительным пространственным неоднородностям, так как их длина когерентности является величиной одного порядка по сравнению с шириной ГД, межслойными, межатомными и межэлектронными расстояниями. Это приводит к сильной зависимости магнитотранспортных свойств ВТСП от наличия дефектов, в частности, от плотности и пространственного распределения ГД. Следует отметить, что наличие ГД присуще самой природе ҮВСО ВТСП, так как двойниковые домены (монодомены, кристаллиты, суб- и нанокристаллиты) образуются в результате структурного фазового перехода из тетрагонального (несверхпроводящего) в орторомбическую (сверхпроводящую) фазу при температуре $\sim 7000^{\circ} \mathrm{C}$ и/или изменением стихиометрии образцов путем легирования [2-10]. Так как свойства ГД ярко проявляются также и в других купратах (лучше в соединениях $\mathrm{LaSrCuO}$ ), а также в пниктидах железа, то от ГД избавиться не удастся и с ними, придется считаться. Макроскопические свойства ВТСП изучены достаточно подробно. Однако из-за возникновения серьезных экспериментальных проблем при исследовании магнитотранспортных свойств двойников, микроскопические процессы, происходящие внутри двойников, изучены недостаточно. Проявление большого интереса к двойникам и ГД объясняется тем, что именно двойники 
являются более упорядоченными, менее дефектными системами с наиболее высокими критическими сверхпроводящими параметрами, а ГД играют большую роль в формировании микроскопических и макроскопических параметров ҮВСО ВТСП. Кроме того, в результате квантового ограничения сверхпроводящего параметра порядка на ГД, приводящего к низкой величине $J_{c}$ в междоменном и в внутридоменном пространстве ВТСП, выращивание границ двойников и/или ГД с помощью легирования или термообработки создает возможность настраивать электронные свойства ВТСП и дать важную физическую информацию для разработки ВТСП с током, близким к току распаривания Гинзбурга-Ландау $J^{G L}[11]$ и квантовых устройств на основе ВТСП [10,12]. Так например, в связи с обнаружением в двойниковых, ромбических, недостаточно допированных кристаллах $\mathrm{Ba}\left(\mathrm{Fe}_{1-x} \mathrm{Co}_{x}\right){ }_{2} \mathrm{As}_{2}$ модулирования плотности сверхтекучей жидкости с помощью ГД [13-15], задачи образования с помощью ГД доменной микроструктуры в электронной подсистеме ВТСП, приводящие к неоднородному пространственному распределению плотности носителей заряда сверхтока на ГД и вблизи нее, снова стали актуальными $[15,16]$. Обнаруженные полосы повышенной диамагнитной восприимчивости, которые исчезали в тетрагональных передопированных кристаллах $\mathrm{Ba}\left(\mathrm{Fe}_{1-x} \mathrm{Co}_{x}\right)_{2} \mathrm{As}_{2}$ обосновалось тем, что эти полосы соответствуют повышенной плотности сверхтекучей жидкости на ГД $[13,14]$. Дальнейшая проверка гипотезы образования с помощью ГД доменной микроструктуры в электронной подсистеме ВТСП проводилась путем воздействия на двойниковых доменов и ГД фронтом бегущей затухающей магнитной волны [11,17-19]. Такая методика дала возможность выделить границу раздела вихревых и мейснеровских областей (interface between vortex and Meissner regions (IVMR)), движение которой вокруг ГД позволило изучить распределение плотности сверхтока вблизи и на ГД в зависимости от периода решетки ГД [11,17-19]. Таким образом, создание высокоинформативной прецизионной методики диагностики сверхпроводников на принципиально другой физической основе позволяющей различными способами: отчетливо обнаружить двойники и ГД во всех видах структур YВСО ВТСП; изучить физические процессы в двойниках вблизи и на ГД; определить геометрические размеры и критические параметры двойников; выяснить степень неоднородности ВТСП-образцов; установить период распределения ГД может иметь большое научное и прикладное значение (см. [11,17-19] и приведенную там литературу). Наличие такой методики диагностики ВТСП позволит установить обратную связь управления технологическим циклом изготовления ВТСП-материалов. Это создаст возможность регулировать симметрией решетки кристалла при структурном фазовом переходе из тетрагональной в орторомбическую фазу, контролировать процесс изменения стехиометрии образцов путем допирования или изменения содержания кислорода при кристаллизации двойников с помощью термообработки образцов при $T<600-700^{\circ} \mathrm{C}$. В результате методика позволит создать возможность одновременного исследования кристаллической, магнитной и электронной микроструктур ВТСП-образцов и выяснить особенности взаимодействия указанных микроструктур, дающих ключ к пониманию механизма ВТСП. В работах [11,17-19] для обнаружения ГД и исследований физических процессов вблизи и на ГД (хорошо демонстрирующих проявление ГД в микромасштабах в пленочных и массивных YВСО ВТСП образцах) нами были исследованы локальные характеристики образцов с помощью преобразователя Холла (ПХ) в рамках различных вариантов: локального поля - локальная регистрация, и нелокального поля локальная регистрация. В этих исследованиях локальное поле для воздействия на образец было создано с помощью осциллирующего затухающего локального магнитного поля, а в варианте с нелокальным полем воздействие на образец осуществлялось с помощью высокостабильного однородного магнитостатического поля. В настоящей работе мы предлагаем более чувствительный метод с повышенным пространственным разрешением для одновременного исследования макроскопических и микроскопических характеристик ВТСПобразцов произвольной формы, позволяющем выяснить объемный и локальный характер проявления ГД в образце. Метод основан на способе воздействия на образец нелокальным высокостабильным однородным магнитостатическим полем и нелокальным интегральным способом регистрации с помощью высокочастотной индуктивности сигнала магнитного отклика в виде динамической комплексной магнитной проницаемости $\mu_{v}$. Это позволяет одновременно получить богатую информацию, как об интегральных, так и об локальных характеристиках образца. Для этого путем сканирования объема образца с помощью IVMR можно будет на разных точках поверхности образца исследовать распределение магнитного потока (как на краю, так и внутри ВТСПобразца) и изучить взаимодействие внешнего магнитного поля с экранирующими мейснеровскими токами. Для уменьшения влияния краевых эффектов на локальные характеристики образцов (которые существенны при измерениях в однородных полях) разработанная методика для создания локального магнитного поля основана на режиме ZFCMFA (zero field cooling with magnetic flux accumulation) [11,17-19]. Предлагаемая методика лишена недостатков, присущих методу, использующему однородные внешние поля для определения характеристик образцов с большим размагничивающим фактором так как в режиме ZFCMFA методика позволяет предварительно регулировать поверхностный энергетический барьер для вхождения вихревых линий в сверхпроводник. Создается возможность поэтапно селективно выделить ГД путем осуществления в них захвата магнитного потока (ЗМП) и определить очень важную для сверхпроводников величину - локальный энергетический барьер образования в образце смешанного состояния [20,21]. 
Исходя из того, что структурный анализ с помощью рентгеновских и электронных микроскопов, не позволяющий одновременно воздействовать на образец магнитным полем, позволяет хорошо обнаруживать ГД только в монокристаллических ҮВСО и в зернах поликристаллических ҮВСО ВТСП, а в эпитаксиальных пленках ҮВСО обнаруживать лишь дислокации, микротрещины, поры и другие линейные и точечные дефекты, а не как ГД, целями настоящей работы являются следующие.

1. Демонстрации объемного характера скачкообразного распада образца на двойники с близкими размагничивающими факторами $(n)$, приводящие к скачкообразному проникновению магнитного потока в ҮВСО ВТСП.

2. Более подробно выяснить причины об избирательном проявлении ГД в ВТСП-материалах разных микроструктур в зависимости от способов их синтеза, а также выяснение причин проявления ГД во всех микроструктурах лишь после приложения к ВТСП-образцу магнитного поля;

3. Интегральным способом измерения значения критических полей скачкообразных квантовых фазовых переходов в вихревой системе образца.

\section{2. Экспериментальные методики и образцы}

\section{1. Образцы}

Для выяснения вопроса о необнаружении ГД в YВСО эпитаксиальных пленках разными микроскопами высокого разрешения и наоборот их обнаружение в YВСО монокристаллических образцах и зернах ҮВСО поликристаллических образцов мы проводили исследования магнитных свойств ВТСП на ҮВСО-образцах с разными микроструктурами и с разной высотой краевого барьера, объемным пиннингом, размагничиванием. Образцы в форме диска диаметром $8 \mathrm{~mm}$, изготовленные из массивных текстурированных (ось $c$ перпендикулярна плоскости образца) квазимонокристаллическых поликристаллических (образец № 1), нетекстурированных керамических YВСО и эпитаксиальных пленок YВСО (образцы № 2, № 3) имели толщину $\approx 0.7-4.2 \mathrm{~mm} \quad$ и $\approx 0.4-0.5 \mu \mathrm{m}$ соответственно. Для эпитаксиальных пленок были получены значения температур $T_{c} \approx 92 \mathrm{~K}$ и $\Delta T_{c} \approx 0.6 \mathrm{~K}$, а для массивного образца $-T_{c} \approx 92 \mathrm{~K}$ и $\Delta T_{c} \approx 1 \mathrm{~K}$. Критическая температура измерялась с помощью резонансного измерителя индуктивности чувствительностью $\approx 1 \mu \mathrm{H}$ в частотном диапазоне $(355-505) \mathrm{kHz}$ из температурной зависимости индуктивности микросоленоида $\ell(T)$, где $\ell \approx 65 \mu \mathrm{H}$.

\subsection{1. Характеристики текстурированного квазимонокристаллического YBCO поликристаллического образца}

Текстурированные квазимонокристаллические YВСО поликристаллические образцы вырезались алмазной фрезой из заготовки цилиндрической формы. Плавленые текстурированные квазимонокристаллические образцы синтезировались с помощью затравки, устанавливаемой сверху при высокой температуре. С помощью оптического микроскопа в поляризованном свете отчетливо наблюдались блестящие монокристаллические блоки (монодомены) размером $\approx 0.11 \mathrm{~cm}^{2}$, разделенные узкими включениями зеленого оттенка. Это подтверждалось картографированием ЗМП с помощью ПХ. С целью исключения неоднородности распределения кислорода на торцах по отношению к объему, торцевые поверхности удалялись алмазным резцом. Критический ток, измеряемый по четырехзондовой схеме на мостиках, изготовленных из квазимонокристаллическых YВСОобразцов при $T=77.4 \mathrm{~K}$ в поле Земли, составляли $\approx 5.7 \cdot 10^{3} \mathrm{~A} / \mathrm{cm}^{2}$. На поверхности монодоменов квазимонокристаллического ҮВСО наблюдались ГД. Критический ток, измеряемый по четырехзондовой схеме на мостике, изготовленном из монодомена, составил $\approx 6 \cdot 10^{5} \mathrm{~A} / \mathrm{cm}^{2}$ при $77.4 \mathrm{~K}$ в поле Земли. Анизотропия сопротивления, измеренная на поверхности монодомена, составила $\approx 3$, что говорит о малом числе ГД в монодомене. Текстурированные поликристаллические и нетекстурированные керамические образцы состояли из двойников размерами $\sim 1 \mu \mathrm{m}$.

\subsection{2. Характеристики эпитаксиальных пленок YBCO}

Эпитаксиальные пленки ҮВСО (образец №2) разных толщин с ориентацией оси $\vec{c}$ перпендикулярно плоскости подложки были получены методом магнетронного реактивного распыления на постоянном токе стехиометрической ҮВСО мишени высокой плотности в кислородосодержащей атмосфере при давлении $3.5 \mathrm{mbar}$ (350 Рa). Использовались подложки $\mathrm{NdGaO}_{3}$ (110) цилиндрической формы диаметром $8 \mathrm{~mm}$ и толщиной $d$ до $1 \mu \mathrm{m}$. Температура подложки составляла $800^{\circ} \mathrm{C}$. Рентгеноструктурый анализ полученных пленок показал наличие единственной ориентации (0001). Полуширина кривой качания составила $0.2^{\circ}$. По уширению дифрационной линии (0005) по формуле Шеррера был определен средний размер областей когерентного рассеяния. Он составил около $20 \mathrm{~nm}$. Это говорит о наличии значительного количества малоугловых границ. Эпитаксиальные пленки YВСО (образец №3) цилиндрической формы диаметром $8 \mathrm{~mm}$ и толщиной $h$ до $1 \mu \mathrm{m}$ и с ориентацией оси $c$ перпендикулярно плоскости подложки также были получены лазерным распылением на подложке $\mathrm{NdGaO}_{3}$ (110) стехиометрической YВСО мишени высокой плотности. Исследование на рентгеновском дифрактометре показало, что пленки имеют низкую дефектность. Исследования с помощью растрового электронного микроскопа высокого разрешения и токовых измерений показали, что пленки имеют анизотропию в плоскости $a b$, сравнимую с анизотропией монокристалла. Критический 

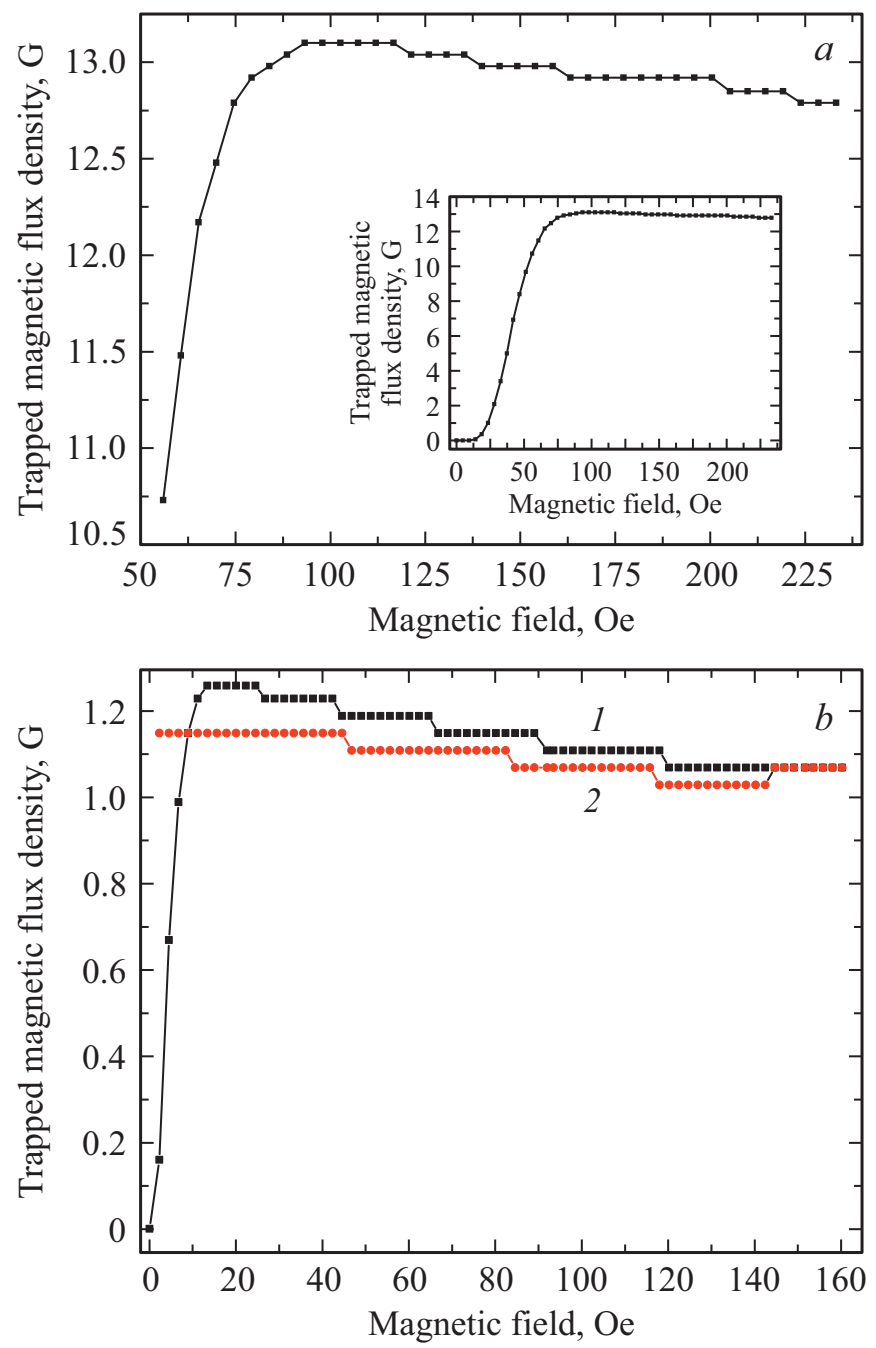

Рис. 1. Изотермические магнитополевые зависимости $B_{t r}\left(H_{0}\right)$ для эпитаксиальных пленок YВСО: $a$ ) Хвостовая часть зависимости $B_{t r}\left(H_{0}\right)$ в увеличенном масштабе для образца № 2, полученное методом магнетронного реактивного распыления. На вставке приведена зависимость $B_{t r}\left(H_{0}\right)$ целиком; $b$ ) для образца № 3, полученная лазерным распылением. Пленки диаметром $8 \mathrm{~mm}$ и толщиной $h$ до $1 \mu \mathrm{m}$ с ориентацией оси $c$ перпендикулярно плоскости подложки напылялись на подложке $\mathrm{NdGaO}_{3}$ (110) стехиометрической YВСО мишени высокой плотности. Температура $T=77.4 \mathrm{~K}$.

ток, измеряемый по четырехзондовой схеме на мостиках, изготовленных методом фотолитографии и жидкого травления, при $77.4 \mathrm{~K}$ составил $\approx 5 \cdot 10^{6} \mathrm{~A} / \mathrm{cm}^{2}$ в поле Земли [22,23]. Обычно структурный анализ эпитаксиальных пленок с помощью рентгеновских и электронных микроскопов, которые не позволяют одновременно подействовать на образец магнитным полем, позволяют хорошо обнаружить только дислокации, микротрещины, поры и другие точечные дефекты, а не как ГД. В пленке мелкие ГД замаскированы с стороны протяженных ГД и они хорошо проявляются только при приложении к пленке магнитного поля [24,25].
На рис. 1 для образцов № 2 и 3 приведены изотермические магнитополевые зависимости $B_{t r}\left(H_{0}\right)$ : a) хвостовая часть зависимости $B_{t r}\left(H_{0}\right)$ в увеличенном масштабе для образца № 2 полученная методом магнетронного реактивного распыления. На вставке приведена зависимость $B_{t r}\left(H_{0}\right)$ целиком; b) для образца № 3 полученная лазерным распылением. Как видно из рис. 1 на зависимости $B_{t r}\left(H_{0}\right)$ хорошо проявляются ступени. Оценка для эпитаксиальных пленок показала, что $B_{t r}^{\max }(0)=J_{c} d \approx 200 \mathrm{G}$ для образцов № 2 и 3. Полученные результаты сильно расходятся с экспериментальными результатами $B_{t r}^{\max }(0) \approx 13.04 \mathrm{G}$ для образца № 2, приведенные на рис. $1, a$, и $B_{t r}^{\max }(0) \approx 1.34 \mathrm{G}$ для образца № 3, приведенные на рис. $1, b$. Поля рассеяния ЗМП в пленке в основном замыкаются через ГД и другие дефекты внутри пленки. Такой результат показывает, что вопреки транспортным измерениям и показаниям рентгеновского дифрактометра и электронного растрового микроскопа, в сильных магнитных полях ГД в исследованной эпитаксиальной пленке ведут себя аналогично слабым связям в поликристаллических пленках. Высокий уровень плотности ЗМП демонстрирует более высокую степень дефектности и большое количество междоменных (островковых) протяженных слабых связей. Это притесняет эффекты, вызванные с ГД и вызывает низкую амплитуду скачков в пленках полученные с помощью магнетронного распыления (см. рис. 1,a). В пленках полученный лазерным распылением уровень плотности ЗМП намного ниже (см. рис. $1, b)$, что позволяет более ярко проявляться ГД [11,17-19].

\section{2. Детали әксперимента}

Исследование изотермических магнитополевых зависимостей: индукции $B\left(H_{o}\right)$, плотности ЗМП $B_{t r}\left(H_{o}\right)$, динамической комплексной магнитной проницаемости $\mu_{v}\left(H_{0}\right)$ проводились в режимах ZFC (zero field cooling) и ZFCMFA с помощью следующих способов:

- нелокальное поле - нелокальная регистрация, когда внешнее поле однородно, а сигнал отклика регистрируется с помощью объемной высокочастотной комплексной магнитной проницаемости;

- нелокальное поле - локальная регистрация, когда внешнее поле однородно и постоянно, а отклик регистрируется с помощью ПХ.

a) Режим ZFC - образец охлаждался до температуры жидкого азота в нулевом магнитном поле, затем подавалась ступенька внешнего магнитного поля длительностью $5 \mathrm{~min}$ и через $5 \mathrm{~min}$ после снятия поля в центре на поверхности образца измерялась $B_{t r}$. Далее образец нагревался до температуры выше $T_{c}$, и эксперимент повторялся для другой ступеньки $H_{o}$.

б) Режим ZFCMFA отличается от режима ZFC тем, что после первоначального захвата без изменения величины $B_{t r}$ и без нагревания образца подавалось поле $H_{o}$ следующей ступени длительностью $5 \mathrm{~min}$ и через 5 min после снятия поля измерялась суммарная $B_{t r}$ и т. д. 
В режиме ZFC подачей к образцу ступени поля $H_{0}$ обеспечивалось непосредственное взаимодействие магнитного поля с образцом, находящимся в мейснеровском состоянии, и тем самым исследовались макроскопические свойства образца. В режиме ZFCMFA (подробнее см. работы $[23,24]$ и ниже) производится поэтапное разрушение слабых связей полями рассеяния захваченных в пленке вихрей и, по возможности, обеспечение взаимодействия внешнего поля с раздельными двойниками. Таким образом, режим ZFCMFA, в отличие от режима $\mathrm{ZFC}$, позволяет кроме макроскопических свойств ВТСП изучить также физические процессы внутри образцов.

Наблюдение с помощью локального и нелокального (интегрального) способа над процессами распада образца на двойники, приводящее к скачкообразному проникновению магнитного потока в образец при ее ,делении“ и измерении термодинамических первых критических магнитных полей $H_{i c 1}$ двойников, а также сопоставление полученных результатов друг с другом очень важно так как:

- учитывается реакция одновременно всех двойников образца на суммарное поле $H(t)$, состоящее из высокостабильного однородного статического и переменного магнитных полей;

- одновременно изучается взаимодействие индуцированными внешним магнитостатическим полем мейснеровских макроскопических и микроскопических экранирующих токов и индукционных переменных токов;

- одновременно изучается взаимодействие всех вихрей как друг с другом, так и с мейснеровскими токами двойников и переменными индуктивными токами;

- увеличивается сигнал отклика из-за увеличения числа двойников в группе двойников с близкими $n$.

Для исследования магнитополевой зависимости динамической комплексной магнитной проницаемости $\mu_{v}=\mu_{v}^{\prime}+i \mu_{v}^{\prime \prime}$ к образцу прилагалось суммарное магнитное поле $H(t)$, состоящее из магнитостатического поля амплитудой $H_{o}$ до $1.6 \mathrm{kOe}$ и переменного магнитного поля амплитудой $H_{1} \approx 3 \cdot 10^{-3} \mathrm{Oe}[26]$ :

$$
H(t)=H_{o}+H_{1} \cos (\omega t+\varphi), \text { где } H_{o} \gg H_{1} .
$$

Исследование изотермической магнитополевой зависимости объемной высокочастотной динамической комплексной магнитной проницаемости $\mu_{v}\left(H_{0}\right)=$ $=\left(B / H_{0}\right)\left(H_{0}\right)$ YВСО образца № 1 , находящегося внутри микросоленоида, индуктивность которого составляла $L_{k}\left(\mu_{v}, H_{0}, T, B_{t r}\right)$, измерялась с помощью высокочастотного резонансного измерителя индуктивности в частотном диапазоне $355-505 \mathrm{kHz}$ в режиме ZFCMFA. Процедура измерения $L_{k}\left(\mu_{v}, H_{0}, T, B_{t r}\right)$ заключалась в следующем.

Сначала при комнатной температуре измерялась индуктивность микросоленоида с ҮВСО образцом № 1 диаметром $D \approx 6 \mathrm{~mm}$ и толщиной $h \approx 4.2 \mathrm{~mm}$. Для этого путем изменения емкости $C_{k}$ в $L_{k} C_{k}$ контуре достигался резонанс, при котором разница рабочей и резонансной частоты составляла $\Delta f=f_{w}-f_{\text {res }}=0$. Измеренное значение $L_{k}$ составляло $\approx 68.53 \mu \mathrm{H}$. Затем индуктивность измерялась после охлаждений в нулевом магнитном поле до температуры $77.4 \mathrm{~K}$. Из-за диамагнитного экранирования образца индуктивность подала и это привадило к уходу резонансной частоты. Вращением переменной емкости $C_{k}$ снова достигалось условие резонанса в $L_{k} C_{k}$ контуре при котором $\Delta f=0$, что соответствовало $L_{k} \approx 37.26 \mu \mathrm{H}$. После этого прикладывалась ступенька однородного постоянного поля $H_{0}$ длительностью 5 min и измерялся уход резонансной частоты $\Delta f_{u}$ при присутствии поля, затем через $5 \mathrm{~min}$ после снятия поля повторно измерялся уход резонансной частоты $\Delta f_{t r}$, вызванный ЗМП в образце. Далее без нагревания образца подавалась следующая ступенька поля и измерение повторялось. Чувствительность резонансного измерителя индуктивности составляла $\approx 0.1 \mu \mathrm{H}$ в частотном диапазоне $\approx 1.1-1.5 \mathrm{MHz}$ и $\approx 1 \mu \mathrm{H}$ в частотном диапазоне $\approx 355-505 \mathrm{kHz}$.

Измерения зависимостей $B_{t r}\left(H_{o}\right)$ для образцов № 2,3 проводились в режимах ZFC и ZFCMFA, когда к образцу подавались ступени осциллирующего, затухающего по амплитуде локального магнитного поля и высокостабильного однородного магнитостатического поля $\Delta H_{0}$ величиной до $1.6 \mathrm{kG}$, при температуре жидкого азота, с помощью ПХ с размерами рабочей области $1.5 \times 0.5,0.1 \times 0.05 \mathrm{~mm}^{2}$ и коэффициентами преобразования $\approx 80-120 \mu \mathrm{V} \cdot \mathrm{mT}^{-1}$. Установка $[27,28]$ позволяла регистрировать сигналы ПХ с чувствительностью $\approx 2.5 \cdot 10^{-3} \mathrm{G}$. Магнитное поле было направлено перпендикулярно к плоскости образцов. Компонента поля Земли $H_{z}$ компенсировалась катушкой, коаксиальной соленоиду, задающему внешнее магнитное поле.

Пространственные разрешения используемых методик и точность измерения периода ГД также зависят от длительности подачи ступени и времени после снятия ступени поля и начала измерения, так как чем больше $t$, тем меньше влияние релаксационных процессов (время входа потока в образец и время выхода потока из образца) на результат измерения. Обычно за время $t=5 \mathrm{~min}$ заканчивается быстро релаксирующая часть плотности ЗМП и в образце устанавливается „жестко“ закрепленная вихревая решетка. Функционирование выше описанных методик в режиме ZFCMFA хорошо демонстрирует рис. 2 согласно которому путем первоначального ЗМП в образце искусственно создается магнитный барьер для входа вихрей от следующей ступени поля в виде полей размагничивания от $B_{t r 2}$. В дальнейшем, чтобы произвести ЗМП от следующей ступени поля, сначала необходимо компенсировать поля размагничивания от $B_{t r 2}$ и снять заранее созданный магнитный барьер, а затем увеличивать магнитное давление на экранирующие мейснеровские токи двойников до тех пор, пока не произойдет распад образца на очередные более мелкие группы двойников с близкими $n$. Суммарное поле ступе- 


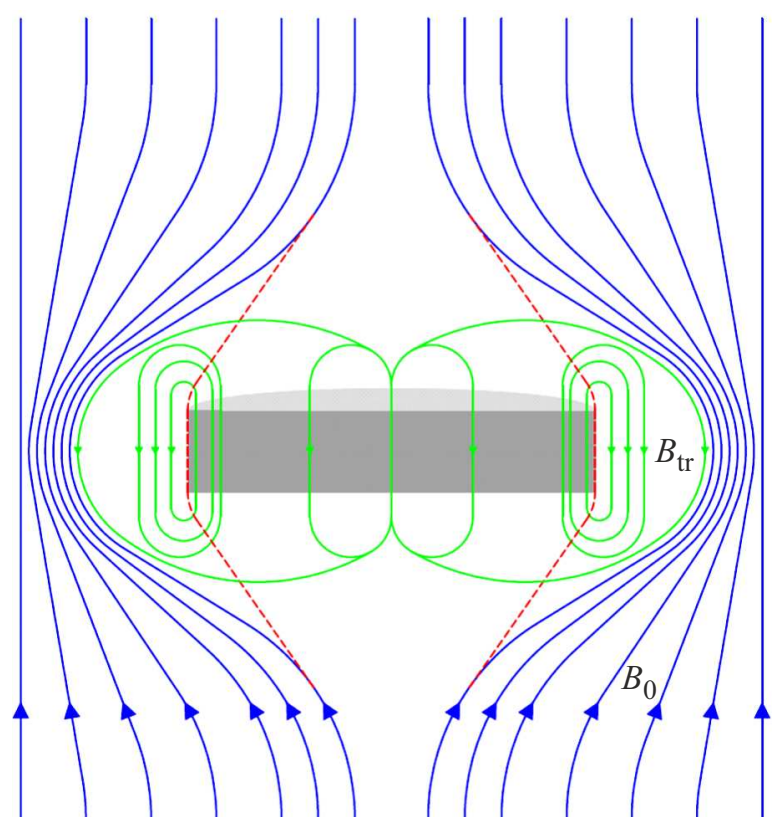

Pис. 2. Качественная картина, согласно которой путем первоначального ЗМП в образце искусственно создается магнитный барьер для входа вихрей от следующей ступени поля в виде полей размагничивания от $B_{t r 2}$.

нек составляло

$$
H_{o p}-H_{D B t r 2}=p \Delta H_{o},
$$

где $H_{D B t r 2}$ - поле размагничивания, созданное полем $B_{t r 2} ; \Delta H_{o}$ - амплитуда ступени внешнего магнитного поля, $p$ - число ступенек. Для упрощения процедуры анализа полученных результатов величина ступеней амплитуды поля $H_{0}$ монотонно увеличивалась шаг за шагом на величину $\Delta H_{o} \approx 1-50 \mathrm{Oe}$, а затем таким же образом уменьшалась. С помощью первоначального задания, а затем последовательного суммирования ступенек с заранее определенными $H_{o}$ создавалась возможность сначала фиксировать, а затем передвигать IVMR и следить за движением IVMR в глубь образца и вовнутрь двойников, а затем обратно. Таким образом, зондирование объема образца с помощью IVMR позволяло раздельно исследовать магнитное состояние областей с одинаковыми критическими параметрами, произвести „локальный“ захват потока и изменить топологию ЗМП с помощью фронта поля и с ростом внешнего поля IVMR постепенно локализовать вокруг зон (двойников и ГД) с наиболее высокими критическими параметрами $\left(H_{c 1 i}, J_{c i}, T_{c i}\right)[11,17-19]$. Таким образом, пространственное разрешение используемых методик зависит от шага заданных ступенек поля $H_{0}$, и чувствительности магнитометра, а также от времени воздействия на образец ступени внешнего поля и времени после снятия ступени магнитного поля. На основе процедуры вычитания плотности ЗМП - $B_{t r 1}$, измеренной в режиме $\mathrm{ZFC}$, из величины $B_{t r 2}$, измеренной в режиме ZFCMFA, была создана дифференциальная методика локального приближения [11,17-19]. Это позволяло исключить влияние на результаты измерений поверхностного барьера, краевого и объемного пиннингов, а также внутренних и внешних полей размагничивания образца и двойников. Такая процедура вместе с ступенчатым изменением амплитуды $H_{o}$ приложенного к образцу поля создавала $\delta$ - подобное пространственное распределение ЗМП. Это создавало возможность с более высокой точностью выделить составляющие, связанные с мейснеровскими экранирующими токами образца и ее двойников.

\section{3. Результаты и обсуждение}

На рис. 3 приведены изотермические магнитополевые зависимости индуктивности микросоленоида с образцом № 1: a) $L_{k t r}\left(H_{0}\right) \approx\left(\Delta f_{t r}\right)\left(H_{0}\right)$, измеренное в условиях с ЗМП после снятия внешнего поля; б) $L_{k u}\left(H_{0}\right) \approx\left(\Delta_{f u}\right)\left(H_{0}\right)$, измеренное в условиях присутствия внешнего магнитного поля. Как в прямом ходе при росте поля (кривая 1), так и при обратном ходе изменения поля (кривая 2) на зависимости $\Delta f_{t r}\left(H_{0}\right)$ (рис. 3,a) хорошо проявляются $H_{i c 1}$ двойников, при которых образец скачкообразно распадается на группы двойников с близкими $n[11,17-19]$. На кривых 1 и 2 также хорошо видны протяженные по $H_{0}$ области постоянства $\Delta f_{t r}\left(H_{0}\right)$, что демонстрирует проявление высоких модулей упругости в образце вихревой решетки. Период решетки изменяется спонтанно скачком лишь при распаде образца на очередные группы двойников с близкими $n$. При обратном ходе на кривой 2 также хорошо видны скачки в районе первого критического магнитного поля проникновения магнитного поля в образец $-H_{c 1} \approx 50 \mathrm{Oе}$, поля установления критического состояния в междвойниковом джозефсоновском пространстве $-H_{t j} \approx 25 \mathrm{Oе}$ и первого критического магнитного поля проникновения потока в междвойниковую джозефсоновскую среду $-H_{c 1 j} \approx 0.5$ Оe $[29,30]$. Полученные результаты хорошо согласуются с литературными данными [30]. В области слабых полей результаты отчетливо демонстрируют динамику образования состояния сверхпроводящего стекла [31,32] с соответствующими группами сверхпроводящих контуров (состоящих из двойников, соединенных между собой слабыми джозефсоновскими связями). Контура имеют одинаковые значения $n$ и $H_{i c 1}$ проникновения потока через слабые связи внутри контуров. Образованная в присутствие поля регулярная вихревая решетка вихревой кристалл - плавится после снятия внешнего магнитного поля, переходя в режим течения вихревой жидкости [7,8]. Далее в результате ЗМП в образце с ростом поля происходят скачкообразные квантовые фазовые переходы между вихревыми состояниями вихревой кристалл - сверхпроводящее стекло-вихревое стекло - брэгговское стекло [10,33-41]. Особенности в области полей скачкообразных переходов указанных 

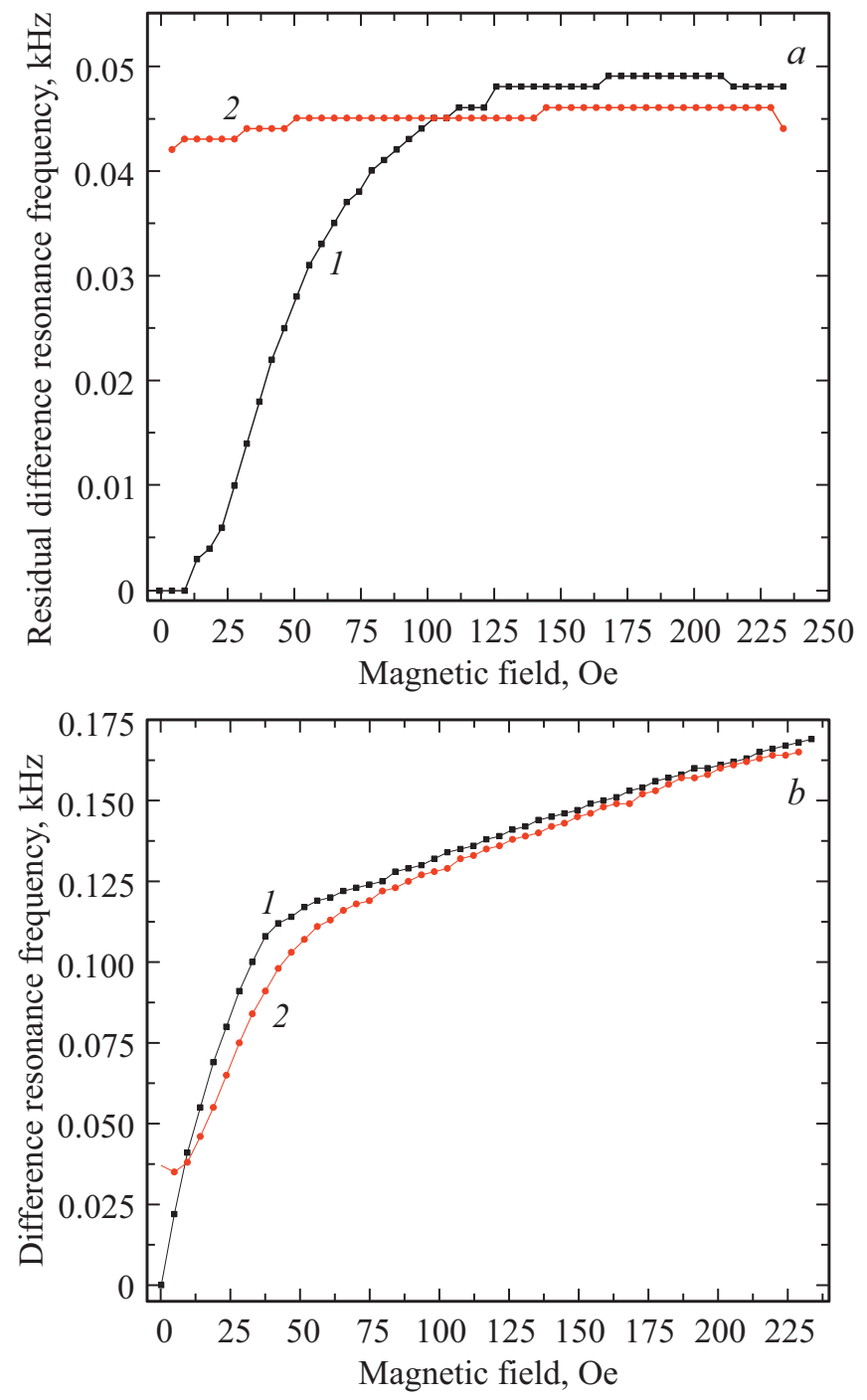

Рис. 3. Изотермические магнитополевые зависимости индуктивности с образцом № 1: a) $L_{k t r}\left(H_{0}\right) \approx\left(\Delta f_{t r}\right)\left(H_{0}\right)$, измеренное в условиях с ЗМП после снятия внешнего поля; b) $L_{k u}\left(H_{0}\right) \approx\left(\Delta f_{u}\right)\left(H_{0}\right)$ в условиях присутствия внешнего магнитного поля. При прямом ходе при росте поля (кривые 1 ) и при обратном ходе изменения поля (кривые 2). Температура $T=77.4 \mathrm{~K}$.

состояний позволяют отчетливо определить ряд критических магнитных полей скачкообразных квантовых фазовых переходов $H_{i c 1} \approx 100,110,125,175,225$ Ое и т.д. Рис. $3, a$ в прямом и обратном ходе развертки поля также позволяет определить $H_{i c 1}$ проникновения потока в образец, его двойники и выявить участки почти линейного диамагнитного экранирования. При росте поля создается спонтанно возникающее самоорганизованное состояние брэгговского стекла, а при обратном ходе искусственно создаются протяженные по полю области состояния идеального брэгговского стекла. С уменышением поля большие по размерам гипервихри [42] выходят из образца и позволяют наблюдать за процессами скачкообразного переключения потока в сверхпроводя- щих контурах в области слабых полей (см. рис. 3, $a$, кривая 2). После снятия поля образованный вихревой кристалл плавится, и в процессе релаксации ЗМП происходит течение вихревой жидкости. Через $5 \mathrm{~min}$ после окончания бистрорелаксирующей стадии ЗМП происходит переход в состояние сверхпроводящего стекла и далее в состояние вихревого стекла. Уменьшение внешнего поля от его максимального значения приводит обратно к перестройке по полю вихрей, захваченных на ГД двойников. Кроме этого, заново происходит захват джозефсоновских и абрикосовских вихрей на междвойниковых плоскостях двойникования и междвойникових стыковых вихрей (intertwine junction vortices (ITJVs)) в точках пересечения ГД [19]. Это приводит к образованию в образце фазозависимых одинаково направленных вихревых массивов. Дальнейшее уменьшение поля приводит к постепенному объединению вихревых массивов в результате вихревой массив занимает весь объем образца и поля рассеяния всех вихрей замыкаются вокруг образца. Таким образом, при росте поля захваченный поток поэтапно переключается на центры с более сильным пиннингом, подавляя захваченный поток в центрах со слабым пиннингом. Об этом свидетельствовало постепенное уменьшение магнитной релаксации вплоть до полного ее исчезновения с ростом поля. При уменьшении поля, захваченный поток сохраняется на центрах с сильным пиннингом и постепенно в захвате участвуют центры со слабым пиннингом. Таким образом, с ростом внешнего поля IVMR постепенно сжимается вокруг зон с наиболее высокими $H_{c 1 i}, J_{c i}, T_{c i}$, а при уменьшении поля потоком заполняется пространство между этими зонами, тем самым все нанодиполи переориентируются и настраиваются по магнитному полю. В традиционных методиках, как при росте, так и при уменьшении поля, в захвате потока участвуют одновременно все центры пиннинга. Исследование магнитной релаксации как при входе потока в образец, так и при выходе потока из образца показало, что экспоненциальная кривая релаксации плотности магнитного потока имеет изломы в точках скачкообразного деления образца на двойники. Выпрямленная логарифмическая кривая релаксации из себя представляла сумму логарифмов с разными коэффициентами. Это демонстрирует, что скорость релаксации разная для разных групп двойников. С уменьшением размеров двойников скорость релаксации подала вплоть до его полной остановки. С целью анализа скоростей релаксации в разных группах двойников были исследованы пространственно-временные характеристики ЗМП путем изменения расстояния между образцом и ПХ. Так как с изменением расстояния до поверхности образца ПХ постепенно чувствует замыкающегося вокруг разных групп двойников фрагменты ЗМП от разных центров пиннинга, то это позволяет селективно выделить разные скорости релаксации для отдельных групп двойников.

На рис. 4 приведены магнитополевые зависимости магнитной проницаемости образца № 1 : a) $\mu_{v t r}\left(H_{0}\right)=$ $=\left(H_{t r} / H_{0}\right)\left(H_{0}\right) \approx\left(\Delta f_{t r} / H_{0}\right)\left(H_{0}\right)$ - когда внешнее по- 
ле выключено и в образце существует только ЗМП; б) $\mu_{v}\left(H_{0}\right)=\left(B / H_{0}\right)\left(H_{0}\right) \approx\left(\Delta f_{u} / H_{0}\right)\left(H_{0}\right)$ в условиях присутствия внешнего магнитного поля. Кривые 1 при росте поля, кривые 2 при спаде поля. Как на зависимостях $\Delta f_{t r}\left(H_{0}\right), \Delta f_{u}\left(H_{0}\right)$ (рис. $\left.3, a, b\right)$ так и на зависимостях, $\mu_{v t r}\left(H_{0}\right), \mu_{v}\left(H_{0}\right)$ приведение на рис. $4, a, b$ хорошо видны особенности и скачки величины $\mu_{v t r}\left(H_{0}\right)$ и $\mu_{v}\left(H_{0}\right)$. Как видно из рис. 4, $a$ при поле $H_{i c 1}$ кривые проходят через максимум, это хорошо демонстрирует, что основная часть ЗМП происходит в протяженном междоменном пространстве и в несверхпроводящих областей образца. Это позволяет отчетливо разделить площади мейснеровских доменов от площадей междоменных и междвойниковых областей. Прохождение через максимум кривых 1 на рис. 4 вызваны двумя конкурирующими процессами, направленными против друг друга. С ростом поля в области слабых полей сначала
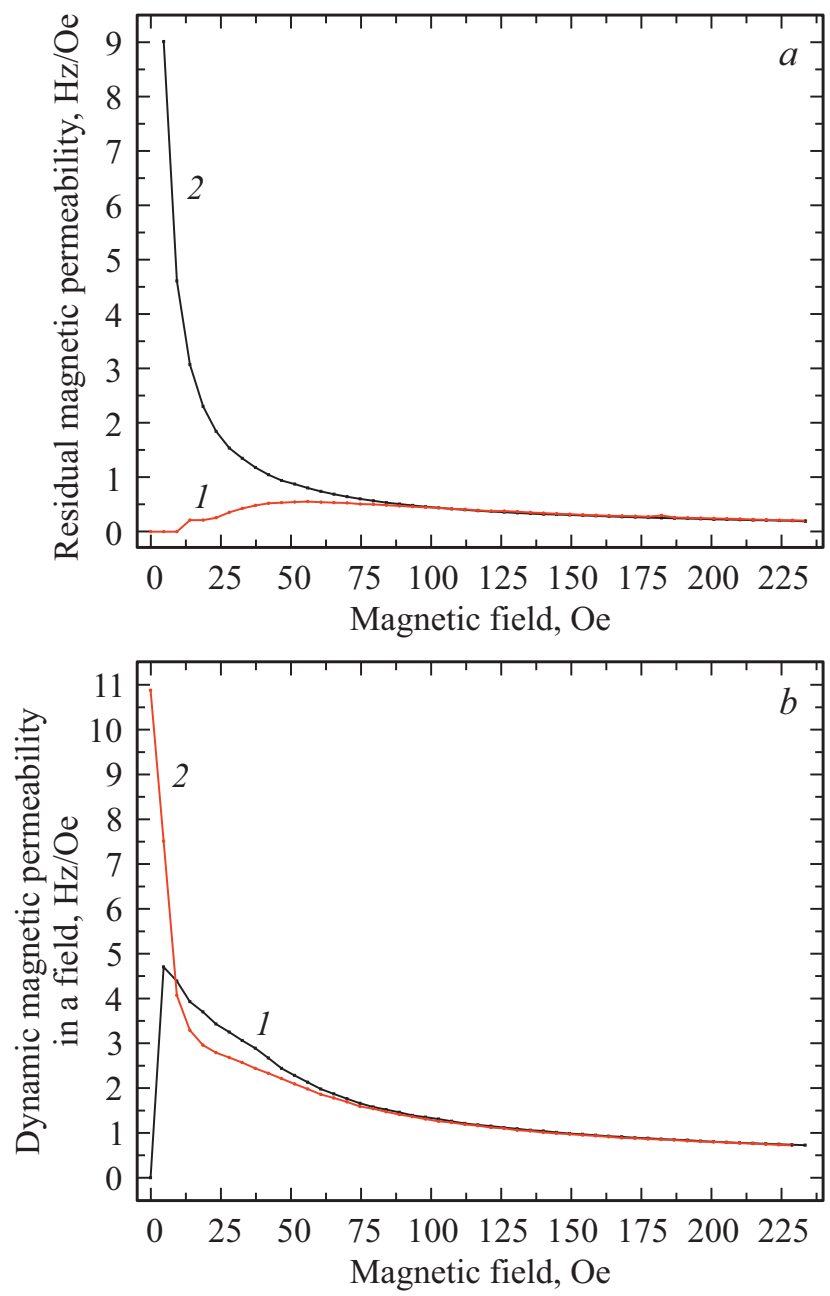

Pис. 4. Магнитополевые зависимости комплексной магнитной проницаемости образца № 1: $a) \mu_{v t r}\left(H_{0}\right)=\left(B_{t r} / H_{0}\right)\left(H_{0}\right)$ $\approx\left(\Delta f_{t r} / H_{0}\right)\left(H_{0}\right)$ когда внешнее поле выключено и в образце существует только ЗМП; $b) \quad \mu_{v}\left(H_{0}\right)=\left(B / H_{0}\right)\left(H_{0}\right)$ $\approx\left(\Delta f_{u} / H_{0}\right)\left(H_{0}\right)$ в условиях присутствия внешнего магнитного поля. Кривые 1 при росте поля, кривые 2 при спаде поля. Температура $T=77.4 \mathrm{~K}$.

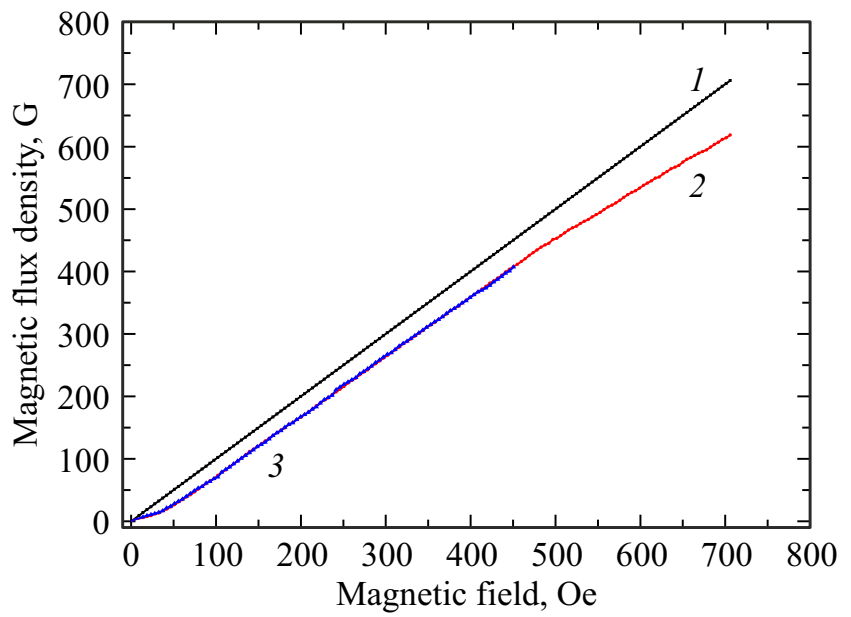

Рис. 5. Измеренные с помощью ПХ типичные магнитополевые зависимости магнитной индукции в центре на поверхности образца № 1: зависимость $B_{1}\left(H_{0}\right)$ для режима ZFC когда в образце отсутствует заранее замороженная вихревая решетка (кривая 2), зависимость $B_{2}\left(H_{0}\right)$ для режима ZFCMFA когда в образце присутствует заранее замороженная вихревая решетка (кривая 1$)$, зависимость $B_{0}\left(H_{0}\right)$ (кривая 3 ). Температура $77.4 \mathrm{~K}$.

ЗМП растет в сверхпроводящих контурах, а затем идет подавление междвойниковых токов контуров с помощью созданных со стороны захваченных в двойниках абрикосовских вихрей и ITJVs междвойниковых стыковых антивихрей (intertwine junction antivortices (ITJAVs)) [19]. В результате при поле $H_{i c 1} \approx 100$ Ое кривая проходит через максимум. Рис. 1,2 хорошо демонстрируют линейные участки диамагнитного экранирования до значения поля $H_{i j}$. При уменьшении поля кривые 2 рис. 4 в области слабых полей демонстрируют быстрый линейный рост, вызванный диамагнитным экранированием внешнего магнитного поля со стороны групп сверхпроводящих контуров. При прямом ходе кривая 1 рис. 4, $a$ до значений полей $H_{0} \approx 12.5 \mathrm{Oe}$ также демонстрирует линейный рост, вызванный диамагнитным экранированием внешнего поля со стороны макроскопических токов текущим по внешнему периметру образца. Затем кривая резко проходит через максимум из-за подавления междвойникових токов контуров со стороны ITJAVs и создание в образце обратно направленного магнитного потока.

На рис. 5 приведены измеренные с помощью ПХ типичные магнитополевые зависимости магнитной индукции в центре на поверхности образца № 1: зависимость $B_{1}\left(H_{0}\right)$ для режима ZFC когда в образце отсутствует заранее замороженная вихревая решетка (кривая 2), зависимость $B_{2}\left(H_{0}\right)$ для режима ZFCMFA - когда в образце присутствует заранее замороженная вихревая решетка (кривая 1 ), зависимость $B_{0}\left(H_{0}\right)$ (кривая 3).

На рис. 6 приведены измеренные с помощью ПХ типичные магнитополевые зависимости локальной динамической комплексной магнитной проницаемости 
для образца № 1: а) зависимость $\mu_{v}\left(H_{0}\right)=\left(B / H_{0}\right)\left(H_{0}\right)$ построенным по данным рис. 5 (кривая 1 режим ZFC, кривая 2 режим ZFCMFA); б) зависимость
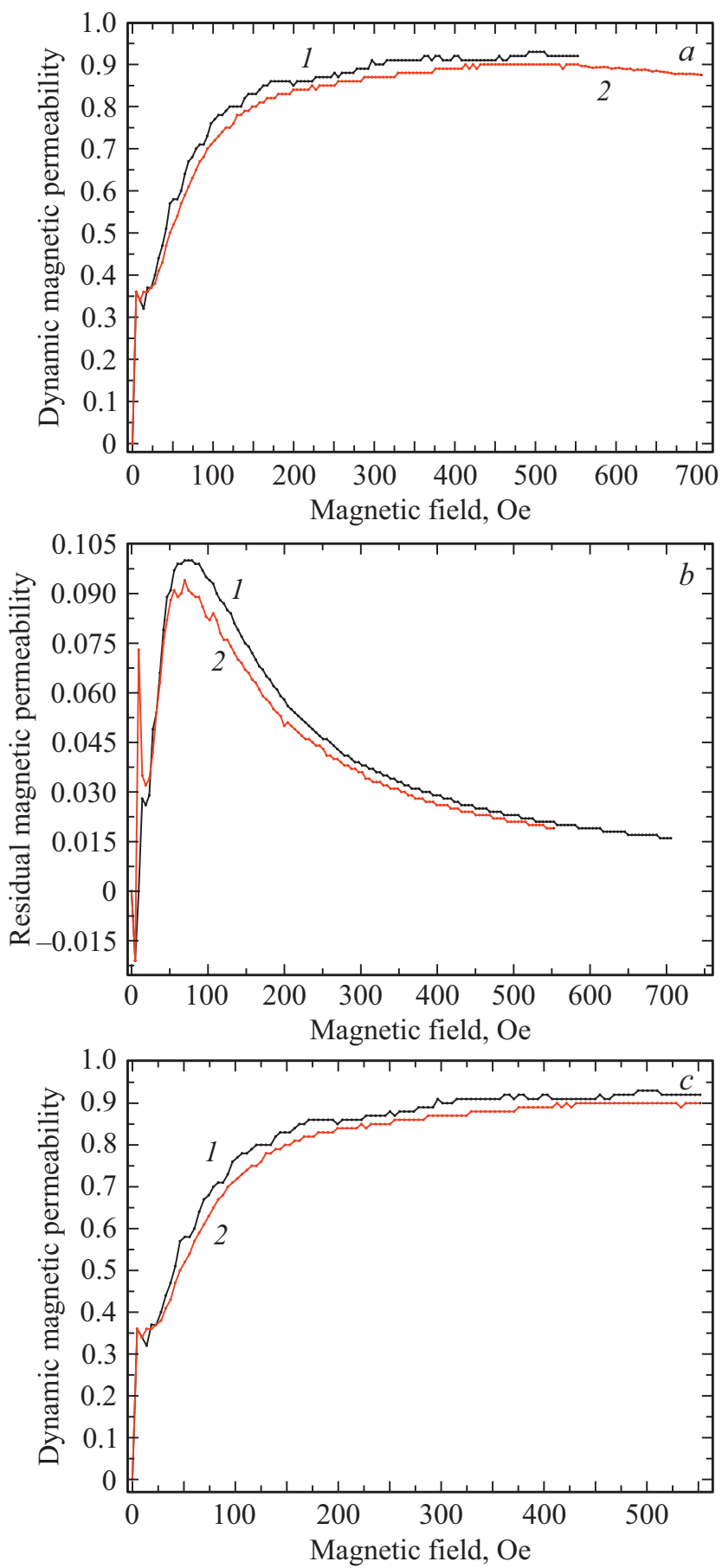

Pис. 6. Измеренные с помощью ПХ типичные магнитополевые зависимости магнитной проницаемости образца № 1: a) зависимость $\mu_{v}\left(H_{0}\right)=\left(B / H_{0}\right)\left(H_{0}\right)$, построенная по данным рис. 5 (кривая 1 режим ZFC, кривая 2 режим ZFCMFA); b) зависимость $\mu_{v t r}\left(H_{0}\right)=\left(B_{t r} / H_{0}\right)\left(H_{0}\right)$ построенная по данным рис. 5 (кривая 2 режим ZFC, кривая 1 режим ZFCMFA); c) зависимость $\mu_{v}\left(H_{0}\right)=\left(B / H_{0}\right)\left(H_{0}\right)$ построенная по данным рис. 5, $a$ (кривая 1 режим ZFC, кривая 2 режим ZFCMFA). Температура $T=77.4 \mathrm{~K}$. $\mu_{v t r}\left(H_{0}\right)=\left(B_{t r} / H_{0}\right)\left(H_{0}\right), \quad$ построенную по данным рис. 5, $a$ (кривая 2 режим ZFC, кривая 1 режим ZFCMFA); в) зависимость $\mu_{v}\left(H_{0}\right)=\left(B / H_{0}\right)\left(H_{0}\right)$, построенную по данным рис. 5, a (кривая 1 режим ZFC, кривая 2 режим ZFCMFA). O реализации в образце состояния сверхпроводящего стекла уже на уровне взаимодействующих сверхпроводящих контуров демонстрирует зависимости на рис. 5, рис. 6 прохождением кривых через минимум в области слабых полей когда потоки, захваченные в сильных контурах меньшего размера постепенно с ростом поля подавляют токи слабых связей слабых контуров больших размеров и переворачивают направление ЗМП в них. В результате усредненные поля измеренные с помощью ПХ становятся знакопеременными. Так как ЗМП измеряется после снятия внешнего поля то в итоге остаются поля размагничивании вызванные мейснеровскими токами двойников, взаимодействующими вихревыми токами вихревой решетки заранее замороженного в образце и в его двойниках. Изменения соотношения долей мейснеровская фаза ГД приводит не только к увеличению критических параметров двойников, но и к более однородному распределению сильных локальных полей близкой величины между двойниками. В результате с ростом поля образец распадается на все более мелкие двойники (суби нанокристаллити) которые задают период все более однородно расположенной вихревой решетки [11,17-19]. Таким образом, усиление ближнего порядка приводит к осуществлению скачкообразного квантового фазового перехода из состояния вихревого стекла в состояние брэгговского стекла. С ростом внешнего поля и распада образца на все более мелкие двойники позволяют определить минимальный период распределения ГД и определить минимальные размеры элементарной ячейки брэгговского стекла. В отличие от искусственно созданного ландшафта центров пиннинга $[43,44]$ в настоящей работе благодаря постепенному переключению ЗМП на естественных периодически расположенных центров пиннинга - ГД продемонстрировано:

1. С распадом образца на двойники при росте поля происходит уменьшение периода распределения ГД (квазипериодический расположенные центры пиннинга) и создается сжимающий по периоду ландшафт центров пиннинга с растущими уровнями локальных поверхностных энергий для входа очередной порции вихрей в образец.

2. При уменьшении поля ландшафт центров пиннинга разжимается как „губка““увеличивая период распределения ГД. Из-за квантования магнитного потока, соизмеримости периода вихревой решетки и квазипериодической сверхструктуры слабых связей, распад образца и проникновение вихрей происходит самосогласованно. Именно с проявлением стеклообразности кристаллографической микроструктуры ВТСП объясняются обнаруженные преобразования в вихревой системе. Как было показано в $[11,17-19]$ и видно из рис. 1 при приложении эпитаксиальным пленкам магнитного поля 
в них также хорошо обнаруживаются двойники и ГД. Вместе с этим учитывая также полученные в настоящей работе результаты для массивных образцов можно полагать следующее. Не обнаруженные обычными методами ГД в пленке объясняются тем, что мелкие ГД замаскированы с стороны протяженных дислокации, междоменнимы протяженными джозефсоновскими переходами и другими плоскими дефектами [24,25]. Магнитное поле и ЗМП подавляет междвойниковые слабые джозефсоновские связи и поля размагничивания двойников через ГД замыкаются вокруг двойников, образуя в образце разнонаправленные диполи тем самим, создают контраст для хорошего проявления в пленке ГД [11,17-19]. Рост поля только приводит к укорачиванию более длинных слабых связей - ГД и к трансформации пространственных масштабов джозефсоновских вихрей. С уменьшением размеров джозефсоновских вихрей они начинают замечать близко расположенные короткие ГД и мелкомасштабные структурные неоднородности образца.

Исходя из выше изложенного ,также необходимо имеет ввиду факты, что в длинных ҮВСО ВТСП лентах второго поколения [45] в области сильных внешних поперечных магнитных полей и собственных полей токов через ленту (вызывающие сильные внешние и внутренние поля размагничивания из-за высокого размагничивающего фактора пленки) течет ток, хотя и меньшей величины (по сравнению с критическими токами эпитаксиальных пленках на подложках меньшего размера), тем не менее достаточный для их использования в сильноточной сверхпроводимости. Это вызывает немало вопросов об общности наличия двойников и ГД во всех видах ҮВСО ВТСП в независимости от способов их построения и технологии получения. На наш взгляд проводимые этими лентами достаточно высокие критические токи, как в собственном, так и во внешним высоких магнитных полях заключается в следующем.

1. В перпендикулярном поверхности пленки магнитном поле из-за высокого $n$ ҮВСО ВТСП ленты второго поколения, пленка распадается на все более мелкие суб- и нанокристаллиты, что приводит к уменьшению степени подавления междвойниковых критических токов $J_{c}$ внешними и внутренними полями размагничивания двойников, которые возбуждались в пленке со стороны внешнего поперечного поля и собственного поля тока через ленту. Таким образом, увеличение степени подавления $J_{c}$ за счет роста внешнего магнитного поля и поля тока через ленту компенсируется уменьшением влияния на $J_{c}$ внутренних полей размагничивания двойников за счет уменьшения $\mathrm{n}$ двойников. Кроме того, высокое значение $J_{c}$ обеспечивается и за счет роста критических параметров и усиления ближнего порядка в стеклообразной кристаллической структуре пленки ленты [11,17-19]. Высокое значение $J_{c}$ обеспечивается также за счет образования в пленке сети каналов протекания охватывающий малоугловых границ [45].

2. Как показано в [19], в точках пересечения ГД образуются жесткофиксированные ITJVs и ITJAVs, отличающейся не только по форме от абрикосовских вихрей, но и могут изменятся по размерам уменьшаясь с ростом поля. Кроме того, также жестко фиксированы положения абрикосовских и джозефсоновских вихрей в пространстве между ITJVs и ITJAVs. Это приводит к тому, что существенно уменьшаются процессы теплового нагрева междвойниковых слабых контактов при перемещения малоподвижных ITJVs, ITJAVs, абрикосовских и джозефсоновских вихрей. Таким образом, уменьшается влияние на $J_{c}$ тепловых эффектов за счет термаактивированного крипа магнитного потока.

3. Так как указанные в пунктах 1 и 2 основные проблемы сведены к минимуму, то остальные всевозможные влияющее на $J_{c}$, незначительные процессы шунтируются с помощью интерслоя и металлической подложки сверхпроводящих лент второго поколения.

4. Как было показано в [2-5] и выше монокристаллические зерна поликристаллических ҮВСО ВТСП и монокристаллические ҮВСО ВТСП содержат в себе большое количество ГД. Из-за этого, хотя в первом приближении их можно считать монокристаллическими, это в действительности далеко не так. Согласно установленным фактам и полученным данным приведенными выше (см. раздел 2.1.1.), критические токи ҮВСО образцов при $T=77.4 \mathrm{~K}$ в поле Земли составили: $\approx 5.7 \cdot 10^{3} \mathrm{~A} / \mathrm{cm}^{2}$ для квазимонокристаллических образцов; $\approx 6 \cdot 10^{5} \mathrm{~A} / \mathrm{cm}^{2}$ для монодоменов; $\approx 5 \cdot 10^{6} \mathrm{~A} / \mathrm{cm}^{2}$ для эпитаксиальных пленок, $\approx 2.2 \cdot 10^{6} \mathrm{~A} / \mathrm{cm}^{2}$ для четырехслойного $\mathrm{YBCO} \mathrm{-}$ интерслой - ҮВСО ВТСП-лент второго поколения толщиной $1 \mu \mathrm{m}$ [46]. Эти токи намного ниже, чем ток распаривания $J_{c}^{G L}(77.4) \approx 1.91 \cdot 10^{7} \mathrm{~A} / \mathrm{cm}^{2}$ в поле Земли. Кроме этого, как было показано в $[11,17,18]$ с ростом поля величина $J_{c}$ меняется от значения $\approx 5.7 \cdot 10^{3} \mathrm{~A} / \mathrm{cm}^{2}$ для образца до $\approx 8.2 \cdot 10^{7} \mathrm{~A} / \mathrm{cm}^{2}$ для суб- и нанокристаллитов размерами $\approx 81 \mathrm{~nm} \mathrm{в} \mathrm{поле}$ $H_{c} \approx 2.82 \cdot 10^{3}$ Ое. Отсюда видно, что токи суб- и нанокристаллитов в поле $H_{c} \approx 2.82 \cdot 10^{3}$ Ое более чем на два порядка превышают критический ток монодомена, измеренный четырехзондовым методом в поле Земли, и превосходят $J_{c}^{G L}$. Исходя из этих данных, можно заключить, что несмотря на усиление критических токов слабых связей с уменышением размеров двойников, они тем не менее распадаются на более мелкие двойники. Сходство результатов, полученных на образцах с различными микроструктурами, строением, геометрическими размерами, формой и технологией их получения также указывает на единый механизм проникновения (выхода), распределения и захвата магнитного потока в них. Следовательно, как наличие слабых связей, так и двойникования скорее всего являются фундаментальным свойством ҮВСО ВТСП. 


\section{4. Заключение}

Таким образом, с помощью интегрального и локального измерения динамической комплексной магнитной проницаемости объемных и пленочных ҮВСО ВТСП отчетливо демонстрирована возможность скачкообразного распада образца на группы двойников с близкими n приводящей к скачкообразному проникновению магнитного потока в образец. Этим показано, что скачкообразный распад образца на двойники и скачкообразное проникновение потока, как в пленочных, так и в массивных образцах имеет объемный характер, следовательно, хотя в пленках глубина проникновения $2 \lambda$ по величине близка к толщине пленки, эффекты размерного квантования, связанные с толщиной пленки, исключаются. Исходя из проведенных исследований, можно полагать, что конкуренция симметрии кристаллической решетки при фазовом переходе из тетрагональной фазы в орторомбическую фазу приводит к образованию в образце группы двойников с квантованными пространственными масштабами. Яркому проявлению ступенек на магнитополевых зависимостях $B_{t r}\left(H_{0}\right), B\left(H_{0}\right),\left(\Delta f_{t r}\right)\left(H_{0}\right)$, $\left(\Delta f_{u}\right)\left(H_{0}\right), \mu_{v t r}\left(H_{0}\right)$ и $\mu_{v}\left(H_{0}\right)$ при образовании вихревой решетки также способствуют квантование магнитного потока и квантованное изменение периода вихревой решетки запиннингованные квазипериодически в образце ГД. С ростом (уменьшением) поля для входа (выхода) очередной порции вихрей в ГД образуется дискретно сжимающийся (разжимающийся) квазипериодический ландшафт центров пиннинга с усиливающимися (ослабевающимися) локальными краевыми барьерами. Это приводит к все более упорядоченному расположению мелких ГД, что усиливает ближний порядок в вихревой решетке тем самым, обеспечивая скачкообразный квантовый фазовый переход из состояния вихревого стекла в состояние брэгговского стекла. Большое фундаментальное значение имеет выяснение соотношения элементарной ячейки кристаллической структуры ВТСП и образованного в нем элементарной ячейки вихревого брэгговского стекла.

\section{Финансирование работы}

Работа выполнена за счет бюджетного финансирования в рамках государственного задания по теме 0030-2019-0014.

\section{Конфликт интересов}

Автор заявляет, что у него нет конфликта интересов.

\section{Список литературы}

[1] J.G. Bednorz, K.A. Muller. Z. Phys. B 64, 189 (1986).

[2] Y. Syono, M. Kikuchi, K. Oh-ishi, K. Hiraga, H. Arai, Y. Matsui, N. Kobayashi, T. Sasaoka, Y. Muto. Japn. J. Appl. Phys. 26, L498 (1987).
[3] G. Roth, D. Ewert, G. Heger, M. Hervieu, C. Michel, B. Raveau, F. D'Yvoire, A. Revcolevschi. Z. Phys. B 69, 21 (1987).

[4] S. Nakahara, T. Boone, M.F. Yan, G.J. Fisanick, D.W. Johnson. J. Appl. Phys. 63, 451 (1988).

[5] А.А. Абрикосов, А.И. Буздин, М.Л. Кулич, Д.А. Купцов. ЖЭТФ 95, 371 (1989).

[6] И.Н. Хлюстиков, А.И. Буздин. УФН 155, 47 (1988).

[7] В.В. Шмидт. Введение в физику сверхпроводников. МЦНМО, М. (2000).

[8] Ю.М. Ципенюк. Физические основы сверхпроводимости. Физматкнига, М. (2003).

[9] M. Eisterer. Phys. Rev. B 99, 094501 (2019).

[10] Y.-H. Zhou, C. Wang, C. Liu, H. Yong, X. Zhang. Phys. Rev. Appl. 13, 024036 (2020).

[11] Kh.R. Rostami. Low Temp. Phys. 177, 99 (2014).

[12] Kh.R. Rostami, I.P. Nikitin. 153, 107423 (2020).

[13] B. Kalisky, J.R. Kirtley, J.G. Analytis, Jiun-Haw Chu, A. Vailionis, I.R. Fisher, K.A. Moler. Phys. Rev. B 81, 184513 (2010).

[14] J.R. Kirtley, B. Kalisky, L. Luan, K.A. Moler. Phys. Rev. B 81, 184514 (2010).

[15] B. Kalisky, JR Kirtley, JG Analytis, Jiun-Haw Chu, I.R. Fisher, Kathryn A. Moler. Phys. Pev. B 83, 064511 (2011).

[16] John M. Tranquada. Physics 3, 41 (2010).

[17] Х.Р. Ростами. Письма в ЖЭТФ. 105, 12, 758 (2017).

[18] Kh.R. Rostami. Int. J. Mod. Phys. B 32, 31, 1850346 (2018).

[19] Х.Р. Ростами. Письма в ЖЭТФ 108, 755 (2018).

[20] A.S. Mel'nikov, Yu.N. Nozdrin, I.D. Tokman. Phys. Rev. B 58, 11672 (1998).

[21] А.Ю. Аладышкин, А.К. Воробьев, П.П. Вышеславцев, Е.Б. Клюенков, А.С. Мельников, Ю.Н. Ноздрин, И.Д. Токман. ЖЭТФ 116, 5(11), 1735 (1999).

[22] М.С. Афанасьев, А.Н. Базлов, В.Н. Губанков, И.М. Котелянский, В.А. Шахунов. Радиотехника 10, 88 (2005).

[23] A. Kuhle, J.L. Skov, S. Hjorth, I. Rasmussen, J. Bindslev. Hansen. Appl. Phys. Lett. 64, 23, 3178 (1994).

[24] Kh.R. Rostami. Am. J. Mod. Phys. 2, 1, 21 (2013).

[25] X.P. Ростами. ФТТ, 55, 9, 1677 (2013).

[26] A.M. Campbell, J.E. Evetts. Critical Currents in Superconductors. Monographs on Physics. Taylor and Francis Ltd, London (1972). 243 p.

[27] Х.Р. Ростами. ПТЭ 2, 112 (2016).

[28] Х.Р. Ростами. ЖТФ 90, 12, 2066 (2020).

[29] G. Deutsher. Physica C 153-155, 15 (1988).

[30] H. Dersch, G. Blatter. Phys. Rev. B 38, 11391 (1988).

[31] C. Ebner, D. Stroud. Phys. Rev. B 31, 165 (1985).

[32] G. Deutcher, K.A. Muller. Phys. Rev. Lett. 59, 1745 (1987).

[33] Ankit Kumar, Sayantan Ghosh, Tsuyoshi Tamegai, S.S. Banerjee. Phys. Rev. B 101, 014502 (2020).

[34] D. Bazeia, M.A. Liao, M.A. Marques, R. Menezes. Phys. Rev. Res. 1, 033053 (2019).

[35] D.K. Nelson. Phys. Rev. Lett. 60, 1973 (1988).

[36] M.P.A. Fisher. Phys. Rev. Lett. 62, 1415 (1989).

[37] A. Zippeliuse, B.I. Halperin, D.R. Nelson. Phys. Rev. B 22, 2514 (1980).

[38] S. Scheide, V.M. Vinokur. Phys. Rev. B 56, 8522 (1997).

[39] V.M. Geshkenbein, L.B. Ioffe, A.I. Larkin. Phys. Rev. B 48, 9917 (1993). 
[40] T. Giamarchi, P. Doussa. Phys. Rev. Lett. 72, 1530 (1994).

[41] T. Giamarchi, P. Doussal. Phys. Rev. B 52, 1242 (1995).

[42] Э.Б. Сонин. Письма в ЖЭТФ 47, 415 (1988).

[43] Y. Schlussel, T. Lenz, D. Rohner, Y. Bar-Haim, L. Bougas, D. Groswasser, M. Kieschnick, E. Rosenberg, L. Thiel, A. Waxman. Phys. Rev. Appl. 10, 034032 (2018).

[44] G. Zechner, W. Lang, M. Dosmailov, M.A. Bodea, J.D. Pedarnig. Phys. Rev. B98, 104508 (2018).

[45] Токонесущие ленты второго поколения на основе высокотемпературных Сверхпроводников / Под ред. А. Гоял. Изд-во ЛКИ, М. (2009). 432 с.

[46] М.Я. Гараева, И.А. Черных, Т.С. Крылова, Р.И. Шайнуров, Е.П. Красноперов, М.Л. Занавескин. Письма в ЖТФ 40, 20, 47 (2014).

Редактор Ю.Э. Китаев 